\title{
TRAJETÓRIA DE EGRESSOS DA PÓS-GRADUAÇÃO DO INSTITUTO NACIONAL DE PESQUISAS ESPACIAIS: UMA FERRAMENTA PARA AVALIAÇÃO
}

\author{
Maria Lígia Moreira* \\ LÉA VeLHO **
}

Recebido: 18 out. 2011

Aprovado: 23 nov. 2011

*Analista em Ciência e Tecnologia. Instituto Nacional de Pesquisas Espaciais. E-mail: mligia@std.inpe.br

** Professora titular em Estudos Sociais da Ciência e da Tecnologia. Departamento de Política Científica e Tecnológica. Universidade Estadual de Campinas, Campinas, SP, Brasil. E-mail: velho@ige.unicamp.br

Resumo: Este trabalho analisa a trajetória acadêmica e o destino profissional dos egressos dos cursos de mestrado e doutorado do Instituto Nacional de Pesquisas Espaciais (INPE). Para isso, foram realizados levantamento e análise dos dados de 1098 egressos, titulados no período 1968 a 2009, nos cursos de Astronomia, Geofísica Espacial, Meteorologia, Engenharia e Tecnologia Espaciais, Computação Aplicada e Sensoriamento Remoto. Os resultados mostram a relevância das atividades de ensino do Instituto para o desenvolvimento da ciência espacial no país, assim como a importância dos mecanismos de avaliação de desempenho e impacto como subsídios ao planejamento e às ações de formação de competências.

Palavras-chave: Egressos. Pós-Graduação. INPE.

\section{TRACKING ALUMNI OF THE NATIONAL INSTITUTE OF SPACE RESEARCH (INPE). A TOOL FOR PROGRAM EVALUATION}

Abstract: This work analyses the academic trajectory and professional activities of space science specialists who received their Masters and PhD degrees in graduate programs offered by the Brazilian Institute for Space Research (INPE). The analysis is based on data about 1,098 graduates who got their degrees in Astronomy, Space Geophysics, Meteorology, Space Technology and Remote Sensing between 1968 and 2009. The results show the relevance of the graduate education they received to the development of activities in space science in the country. It also documents the importance of developing evaluation tools so that graduate programs in general and INPE in particular can better plan its capacity building activities.

Key words: Alumni. Graduate education. INPE.

\section{INTRODUÇÃO}

Durante os últimos quarenta anos o Brasil desenvolveu competências em atividades científicas, tecnológicas e de gestão nas áreas de Meteorologia e Mudanças Climáticas, Sensoriamento Remoto, Ciências Espaciais e Atmosféricas, Engenharia Espacial, Ciência da Computação e Física de Materiais, o que possibilita ao país participar no pequeno grupo de países que desenvolvem atividades espaciais (PNAE, 2005). O Instituto Nacional de Pesquisas Espaci- 
ais - INPE teve e tem papel central no desenvolvimento de tais competências executando ações do Programa Nacional de Atividades Espaciais e atuando na formação de especialistas em vários domínios da ciência e tecnologia espaciais através de seus cursos de pós-graduação stricto sensu (BRASIL.INPE, 2009).

Apesar do número significativo de titulados nos programas - quase 1700 Mestres e Doutores entre 1968 e 2009 - não se conhece o perfil dos egressos de forma sistemática e organizada. De fato, tem sido consistentemente apontado que, quando um programa alcança certo nível de maturidade, é fundamental examinar, avaliar e refletir sobre o sucesso do programa na formação de profissionais e no desempenho dos mesmos. Isso só pode ser feito a partir do mapeamento e análise da trajetória dos egressos (UNDERWOOD et al, 1994; INGRAM et al, 2005). Além disso, os egressos podem se tornar informantes estratégicos sobre o mercado de trabalho, contribuindo para melhorias na formação oferecida. Também importante é o fato de que egressos em posições chave, seja na academia seja em outros setores de atividade, são contatos fundamentais para novos egressos do programa. Todas estas vantagens só podem ser obtidas se o programa de pós-graduação conseguir ter contato, de forma sistemática e contínua, com parte significativa de seus egressos, o que é, reconhecidamente, um problema (DELANEY, 1994; UNDERWOOD et al, 1994).

Para enfrentar tal problema, pelo menos duas ações são necessárias. A primeira é localizar informação atualizada de contato dos egressos e, a partir dela, desenvolver uma base de dados. A segunda é desenhar instrumentos que facilitem e motivem o acesso dos egressos a tal base de dados de forma a mantê-la atualizada. Esses procedimentos podem gerar um importante conjunto de informações para avaliação, planejamento e tomada de decisão não apenas sobre os programas de pós-graduação e apolítica de formação de pesquisadores na área espacial no Brasil, mas também como modelo para programas de pós-graduação de outras áreas. Perguntas como: Onde estão os egressos? Em que estão trabalhando? Que carreiras seguiram? Qual a contribuição do programa para as carreiras seguidas? que nível de envolvimento eles estão dispostos a ter com o programa de pós-graduação? Tais questões, embora importantes para os policy makers e os gestores da pós-graduação, ainda não podem ser respondidas por falta de informação e acompanhamento de egressos.

Neste sentido, este estudo buscou analisar, a partir de dados disponíveis na Plataforma Lattes do CNPq, o perfil e o destino profissional dos egressos dos cursos de mestrado e doutorado do Instituto. Foram realizados levantamento 
e análise dos dados de 1098 egressos, titulados no período 1968 a 2009, nos cursos de Astronomia, Geofísica Espacial, Meteorologia, Engenharia e Tecnologia Espaciais, Computação Aplicada e Sensoriamento Remoto.

A avaliação dos cursos de pós-graduação em funcionamento no país, cuja organização teve início na década de 60 e conta com ações conjuntas da comunidade acadêmica e das agências de fomento nacionais, é, em grande parte, responsável pelos bons resultados do sistema nacional de pós-graduação (MARTINS, 2000; 2002). Contudo, a avaliação de impacto ainda é um desafio para as instituições de ensino e as agências de fomento e regulação.

Os números que descrevem a pós-graduação brasileira são impressionantes. Em 2007, mais de 84 mil estudantes estavam matriculados em cursos de mestrado e mais de 49 mil em cursos de doutorado. No mesmo ano, foram titulados mais de 30 mil mestres e nove mil doutores (BRASIL.CAPES, 2009). O número de docentes na pós-graduação no mesmo ano passava de 50 mil. Esses números chamam a atenção para a questão: Qual o impacto dessa atividade de ensino nas atividades de ciência, tecnologia e inovação do país? De modo geral, há poucas publicações que tratam sobre o destino profissional de mestres e doutores formados pela pós-graduação brasileira, com destaque para a série "A pós-graduação no Brasil: formação e trabalho de mestres e doutores no país", organizada por Jacques Velloso e editada em 2002. Assim, com a publicação deste artigo espera-se contribuir não só para a avaliação dos resultados do esforço do país de formação de recursos humanos na área espacial, assim como para a reflexão sobre a importância do processo de avaliação de resultados na pós-graduação brasileira.

Inicialmente, este estudo faz um breve relato da história e do modelo de avaliação da pós-graduação no Brasil. A seguir, são apresentados os principais pontos da política espacial quando esta trata da formação de competências e, finalmente, são analisados os dados sobre as trajetórias acadêmicas e inserções profissionais dos mestres e doutores formados no INPE. Para essa última parte, que é a contribuição empírica deste estudo, utilizou-se a metodologia descrita na próxima seção.

\section{METODOLOGIA}

Para acessar informações atualizadas dos egressos, partiu-se do pressuposto de que uma parte significativa deles atuava em atividade de pesquisa e, portanto, deveria ter preenchido seus currículos na Plataforma Lattes do CNPq. Atualmente, a base da Plataforma Lattes conta com cerca de $\mathbf{1 . 1 0 0 . 0 0 0}$ cur- 
rículos, sendo que $31 \%$ destes currículos são de doutores, mestres e estudantes de pós-graduação e $59 \%$ de graduados e estudantes de graduação, e $10 \%$ de outros níveis ou não informados (BRASIL.CNPq, 2009). No entanto, uma vez que a postagem do currículo na Plataforma é prerrogativa do pesquisador, não se tem uma amostra homogênea das instituições e cursos, e alguns cadastrados não registram dados importantes como o destino profissional ou, ainda, não mantêm o currículo atualizado.

Para a realização deste estudo buscaram-se informações sobre os titulados nos programas do INPE entre 1968 e 2009, cujos nomes foram informados pelo Serviço de Pós-Graduação do Instituto, nos cursos de Astronomia, Geofísica Espacial, Sensoriamento Remoto, Meteorologia, Engenharia e Tecnologia Espaciais e Computação Aplicada. Dos 1672 títulos emitidos, foram identificados 1485 egressos, dos quais 1098 têm currículo na Plataforma. Inicialmente, uma vez que não se conhecia o comportamento das informações dos currículos, ou se os programas constituíam estratos distintos, e por ser uma população relativamente pequena, decidiu-se extrair os dados de todos os 1098 currículos da Plataforma.

Com o objetivo de atribuir maior grau de confiança ao estudo, tendo em vista que havia 378 egressos sem currículos na Plataforma, assim como havia currículos com informações parcial ou totalmente não identificadas, optou-se por amostrar apenas os currículos que haviam sido atualizados pelo menos uma vez nos últimos três anos. Em conseqüência, o estudo foi realizado com base em 951 currículos dos 1098 existentes.

A definição desta amostragem permitiu realizar a estimativa de erro com base na abordagem da amostragem simples. O erro amostral para uma amostra de tamanho $\mathrm{n}$ frente a uma população $\mathrm{N}$ é dado por:

$$
E_{0}=\sqrt{\frac{N-n}{N^{*} n}}
$$

No caso do estudo, para uma população (N) de 1485 indivíduos, cuja amostra (n) é de 951 indivíduos, fica:

$$
E_{0}=\sqrt{\frac{1485-951}{1485 * 951}}=0,01944 \cong 2 \%
$$

Considera-se que o erro de dois por cento baseado em informações colhidas em currículos é aceitável. Erros de interpretação na extração de dados, erros 
relativos a informações não fidedignas são imponderáveis e, supõe-se, sejam superiores a esta medida.

A classificação da inserção profissional dos egressos foi baseada nos critérios propostos pelo Manual de Frascati (OECD, 2002) ${ }^{1}$ e o Manual de Canberra $(\mathrm{OECD}, 1995)^{2}$, considerando o setor de atuação e atividade econômica da instituição, e função desempenhada pelo egresso, cujo significado adotado neste trabalho refere-se exclusivamente àqueles que concluíram os cursos, embora o termo "egresso" possa ter um sentido amplo para alguns autores, dentre os quais Pena (2000), que o define como "os indivíduos que saíram do sistema escolar por diferentes vias: diplomados, desistentes, transferidos ou reprovados".

\section{BREVE RELATO DA PÓS-GRADUAÇÃO BRASILEIRA}

Foi no período do regime militar que a pós-graduação brasileira se desenvolveu como "patrimônio institucional da qualificação de docentes e como elemento fundamental da criação de um sistema nacional de ciência e tecnologia" (CURY, 2005). A pós-graduação foi regulamentada pelo Conselho Federal de Educação que expressou através do parecer 977 de 03/12/1965 os motivos fundamentais para sua instauração: 1) formar professorado competente para atender à expansão quantitativa do ensino superior garantindo, ao mesmo tempo, a elevação dos atuais níveis de qualidade; 2) estimular o desenvolvimento da pesquisa científica por meio da preparação adequada de pesquisadores; 3) assegurar o treinamento eficaz de técnicos e trabalhadores intelectuais do mais alto padrão para fazer face às necessidades do desenvolvimento nacional em todos os setores.

A formação de produtores do conhecimento - professores, pesquisadores e técnicos de "alto nível" (SOARES et al, 2002) - era necessária à expansão do sistema econômico, expressão da orientação nacionalista do período que, segundo Morel (1979), requeria um número crescente de profissionais criadores, capazes de inventar novas técnicas e processos de produção. A urgência de promover a implantação sistemática dos cursos pós-graduados com o objetivo de formar cientistas, professores, bem como tecnólogos brasileiros de alto padrão através de cursos de pós-graduação era justificada pela necessidade de criar

1 O Manual Frascati foi elaborado pela OCDE, na década de 60, para uniformizar as metodologias de mensuração das atividades de P\&D dos países desenvolvidos. 1963 (1a. ed.), 2002 (6a. ed.).

2 O Manual de Canberra tem por propósito difundir a padronização de uma estrutura conceitual comum para a compilação, análise de perfis e tendências de dados relativos aos estoques e fluxos de recursos humanos em ciência e tecnologia. 
know-how necessário ao desenvolvimento do país, em contrapartida à criação de carreiras profissionais curtas, naquele momento reclamadas para atender às necessidades da indústria e à diversificação do mercado de trabalho ${ }^{3}$.

Além da valorização de recursos humanos de alto nível e a liberação de verbas públicas para sustentação da pós-graduação, dentre os fatores responsáveis pelo desenvolvimento deste sistema no Brasil, está a atuação das agências de fomento ao desenvolvimento científico: a CAPES, voltada à formação do magistério de nível superior, e o CNPq, voltado ao desenvolvimento da ciência e da tecnologia, ambos criados em 1951; a escolha das universidades públicas como o lócus principal das atividades de pesquisa; a autonomia administrativa dos programas de mestrado e doutorado; o processo de avaliação sistemático dos cursos de mestrado e doutorado, iniciado pela CAPES, em 1972, que serviu de orientação às suas políticas; e a criação de inúmeras associações nacionais de pesquisa e pós-graduação em vários ramos do conhecimento. Todos esses fatores contribuíram para que o sistema seja considerado referência entre os países em desenvolvimento (SOARES et al, 2002; SCHWARTZMAN, 2001).

Cury (2005) ratifica a importância das agências de fomento apontada por Soares (2002), e ressalta que a consolidação da pós-graduação acelerou quando a CAPES, o CNPq e outros órgãos públicos ficaram incumbidos pelo decreto-lei no 464, de 11/2/1969, art. 36 (BRASIL, 1969), de promover a "formação e o aperfeiçoamento do pessoal docente de ensino superior" e compor, para tanto, uma política nacional e regional definida pelo CFE e promovida por uma comissão executiva. Do ponto de vista das políticas, entre os anos de 1975 e 2005 foram editados quatro Planos Nacionais de Pós-Graduação que, associados a Planos Nacionais de Desenvolvimento e Planos Básicos de Desenvolvimento Científico e Tecnológico, entre outros documentos, compuseram o conjunto de normas e diretrizes da pós-graduação.

Tais diretrizes e normas estabeleciam, entre várias outras coisas, que o mestrado e o doutorado fossem relativamente autônomos. Podendo ser visto como uma etapa preliminar na obtenção do grau de doutor, o mestrado não constituiria obrigatoriamente requisito prévio para inscrição no curso de doutorado, além de que poderia ser considerado como um grau terminal. O doutorado teria por finalidade "proporcionar formação científica ou cultural ampla e aprofundada, desenvolvendo a capacidade de pesquisa e poder criados nos diferentes ramos do saber" (ALMEIDA JÚNIOR et al, 2005). Apesar

3 Relatório do Grupo de Trabalho da Reforma Universitária, instituído pelo Decreto n. ${ }^{\circ}$ 62.937, de 2 de julho de 1968. 
de ter sido apontado como um possível grau terminal, o mestrado acabou se constituindo, em grande parte dos casos, um estágio para o doutorado.

Nos anos 90 os doutores foram preponderantemente absorvidos pelas universidades enquanto os mestres atuavam em diversos ramos de atividade, com apenas um terço deles nas universidades (BRASIL.V PNPG, 2004). Diante disso, segundo o V PNPG, haveria necessidade de se retornar à flexibilidade prevista no modelo inicial, com mestrado podendo ser interpretado como um grau terminal, de modo a contemplar demandas diferenciadas da sociedade neste nível de formação.

Ao longo de quarenta anos a política de pós-graduação nacional primeiro procurou capacitar o docente do ensino superior, em seguida se preocupou com o desempenho e a qualidade do sistema e, depois, voltou-se para o desenvolvimento da pesquisa nas universidades (V PNPG). Neste período, o sistema cresceu nos seus vários aspectos: número de cursos, número de alunos, matriculados e titulados, em todas as regiões e em todas as grandes áreas do conhecimento. O número de bolsas disponibilizado pelas agências federais também cresceu, embora em ritmo mais lento.

Reconhecido por seus bons resultados, esse sistema tem despertado discussões no meio acadêmico e estimulado as pesquisas e críticas de pesquisadores, pós-graduandos e docentes. Estudos sobre o sistema abordam diferentes aspectos: alguns tratam do financiamento do sistema, incluindo considerações sobre as políticas de financiamento à pesquisa e de concessão de bolsas das agências de apoio à pesquisa e a pós-graduação (VELLOSO; VELHO, 2001; KUENZER; MORAES, 2005; SBPC, 2006); outros tratam da adequação do formato da pós-graduação frente ao cenário científico e tecnológico atual, incluindo temas como a relação ensino e pesquisa, os critérios de avaliação de cursos, o impacto da produção científica nacional; entre outros (PAULA, 2002; VELHO, 2007; SCHWARTZMAN, 2008; BALBACHEVSKY, 2005).

Além destes temas, estudos sobre o impacto do sistema de pós-graduação no desenvolvimento científico e tecnológico do país abordam a necessidade da ampliação da divulgação da informação e do conhecimento científico (SBPC, 2006); a adequação do sistema de classificação dos periódicos científicos chamado Qualis-Periódicos - para fins da avaliação da pós-graduação, considerando as especificidades das áreas de conhecimento (LEAL; COIMBRA JR., 2008; HAYASHI et al, 2006); a criação de indicadores de impacto social dos programas (SÁ BARRETO, 2006; FISCHER, 2005).

Ao lado da importante infraestrutura científica e tecnológica, o sistema de pós-graduação brasileiro tem sua competência reconhecida por possibilitar a 
instalação de competência por todo o país, seja em universidades ou em institutos de pesquisas, embora aquelas tenham sido consideradas, até meados dos anos 90, o principal destino dos egressos (VELLOSO, 2006). Para que a qualidade desse nível de ensino seja atestada, a avaliação realizada pela Capes, segundo a própria agência, deve ser baseada na qualidade e excelência dos resultados, na especificidade das áreas de conhecimento e no impacto dos resultados na comunidade acadêmica e empresarial e na sociedade. Este tem sido um tema central e recorrente nas discussões sobre o sistema de pós-graduação brasileiro.

\subsection{A avaliação da pós-graduação brasileira: pela inclusão da análise de egressos}

A avaliação da pós-graduação, realizada pela Capes a partir de 1976, segundo a própria Agência contribui para aprimorar cada programa, assegurando o parecer criterioso de uma comissão externa sobre os pontos fracos e fortes de seu projeto e desempenho, além de apontar o estágio de desenvolvimento em que o programa se encontra. A manutenção de um banco de dados sobre a situação e a evolução da pós-graduação e o estabelecimento de um padrão de qualidade oferecem subsídios para a definição da política de desenvolvimento da pós-graduação e para a fundamentação das decisões sobre ações de fomento dos órgãos governamentais na pesquisa e na pós-graduação (BRASIL.CAPES, 2009).

No entanto, até o momento a avaliação da pós-graduação está direcionada mais para análise do desempenho dos cursos e menos para a análise do seu impacto. O número de cursos, de bolsas concedidas, e de alunos titulados teve crescimento constante desde a década de 70 , mas a avaliação da agregação de valor desse contingente de pesquisadores no desenvolvimento científico e tecnológico do país ainda é de difícil mensuração.

Uma vez que a ciência e a tecnologia são importantes para o país como fator para a competitividade, o seu desenvolvimento é também relevante no que se refere à responsabilidade social do conhecimento (SOBRAL, 2001). Considerando os novos modos de produção do conhecimento que provoca mudanças na pesquisa tradicional que se realizava, sobretudo, num contexto acadêmico orientado para o próprio processo de conhecimento e não por sua utilidade econômica e social (SOBRAL, 2001; SCHWARTZMAN, 2008; MOREIRA; VELHO, 2008), devem ser considerados pelas agências e pelas instituições que desenvolvem pós-graduação novos modos de avaliação dos seus programas, incluindo o impacto econômico e social, que poderá ser conhecido através 
de um novo modelo de avaliação que se estende aos resultados da formação acadêmica e do trabalho do egresso.

$\mathrm{Na}$ avaliação trienal de 2007 da pós-graduação, a Capes analisou a proposta dos cursos; a infra-estrutura de ensino e pesquisa; a formação, dimensão, composição e dedicação do corpo docente; produção científica de docentes, dos discentes e egressos; a qualidade das teses e dissertações; e também o impacto social de alguns programas. Além do mapeamento do impacto da produção bibliográfica dos egressos até 36 meses após a conclusão do curso, para o qual a Agência sugere às instituições um cadastro dos titulados, para os cursos interdisciplinares o destino dos egressos é um dos critérios da avaliação dos programas consolidados. Contudo, na avaliação de 2007 somente para uma pequena parcela dos cursos avaliados aparece a recomendação de avaliação de destino de egressos. O documento de avaliação da área de Engenharia III, por exemplo, sugere somar as publicações com discentes autores com as dos egressos, que concluíram até os últimos cinco anos (período avaliação trienal mais dois anos anteriores), no quesito qualidade das teses e dissertações e publicações vinculadas. Na área astronomia/astrofísica, a produção dos egressos é somada na produção científica do programa, considerando muito bons os cursos em que uma fração significativa das publicações do programa tem participação discente, e quando esta participação é bem distribuída pelo conjunto de estudantes e egressos. Na área de geociências a participação de estudantes e egressos é pontuada, ressaltando que "O fundamental para os programas é compreender que a participação de discentes e egressos em publicações é altamente desejável e tende a ser cada vez mais valorizada na avaliação" (BRASIL.CAPES, 2007).

Embora o item "destino dos egressos" não tenha sido pontuado, segundo o documento de avaliação trienal da área de Geociências de 2007, estava prevista a avaliação do desempenho do programa na formação de recursos humanos e de nucleação de grupos de pesquisa em outros estados e regiões do país, sendo observados a situação atual e o histórico do programa "como formador de recursos humanos, considerando a inserção dos discentes e egressos no sistema de pesquisa e pós-graduação" (BRASIL.CAPES, 2007). Estes critérios e algumas recomendações expressas nos documentos de avaliação da Capes de algumas áreas apontam para a necessidade de que as instituições mantenham dados sobre a inserção dos egressos. No entanto, como apontado anteriormente, são poucos os dados publicados sobre esse tipo de avaliação de impacto, ainda que fique claro, nos documentos de várias áreas que a informação sobre egressos é altamente desejável para que se possa estimar um aspecto do impacto do sistema nacional de pós-graduação. 


\section{FORMAÇÃO DE RECURSOS HUMANOS PARA A ÁREA ESPACIAL}

As atividades espaciais estão entre o conjunto de conhecimentos e tecnologias considerados estratégicos para o desenvolvimento do país (MCT, 2002). Nesta direção, a política espacial brasileira, desde os primeiros passos de sua constituição, alinhou-se aos programas setoriais prioritários identificados nos Planos Brasileiros de Desenvolvimento da Ciência e Tecnologia (PBDCTs), editados a partir da década de 70, nos quais a formação de recursos humanos foi considerada uma ação estratégica e prioritária. Os objetivos específicos da atual política espacial brasileira são:

a) estabelecimento no país de competência técnico-científica na área espacial, que lhe possibilite atuar com real autonomia;

b) promoção do desenvolvimento de sistemas espaciais, bem como de meios, técnicas e infra-estrutura de solo correspondentes, que venham propiciar ao Brasil a disponibilidade de serviços e informações de sua necessidade ou interesse;

c) adequação do setor produtivo brasileiro para participar e adquirir competitividade em mercados de bens e serviços espaciais.

Entre as diretrizes da Política está também a promoção da formação e o aprimoramento de recursos humanos altamente qualificados, além de parcerias internacionais, integração das universidades e empresas nas atividades espaciais, e promoção, difusão e efetiva utilização das informações técnico-científicas de interesse espacial.

No que diz respeito à formação de recursos humanos, o Programa Nacional de Atividades Espaciais (PNAE) indica que as estratégias para implementação do Programa devem se basear no fortalecimento das instituições, direta ou indiretamente envolvidas com a sua implementação, com ênfase em formação, capacitação e alocação de recursos humanos de modo a favorecer a inovação tecnológica e o aperfeiçoamento da gestão. Entre as diretrizes do PNAE está o investimento, em parceria com o CNPq e a CAPES, na formação de mestres e doutores, incrementando o número de bolsas para o setor espacial nos programas nacionais de pós-graduação, de modo a prover o quadro de especialistas necessários para o desenvolvimento das atividades espaciais.

O Instituto Nacional de Pesquisas Espaciais - INPE, subordinado ao Ministério da Ciência e Tecnologia, e o Departamento de Pesquisas e Desenvolvimento - DEPED, do Comando da Aeronáutica - COMAer, do Ministério da 
Defesa, são os responsáveis pela execução dos principais projetos e atividades estratégicos do PNAE. Cabe ao INPE a execução dos projetos de satélites e cargas úteis e de suas aplicações, bem como das atividades de manutenção e operação da infra-estrutura associada ao desenvolvimento, integração, testes, rastreio e controle de satélites, e da recepção, processamento e disseminação de dados de satélites. É responsabilidade do INPE a coordenação e execução das atividades de pesquisa e desenvolvimento nos campos das ciências e das aplicações espaciais, assim como no das tecnologias de satélites, cargas úteis e domínios correlatos, e a formação de especialistas na área espacial. A seguir, são apresentados e discutidos parte dos resultados desta atividade.

\subsection{A pós-graduação no INPE}

Embora durante a regulamentação da pós-graduação brasileira a universidade tenha sido indicada como o principal lócus dos cursos de pós-graduação, excepcionalmente e mediante parecer de autorização do Conselho Federal de Educação, foi prevista também a realização de pós-graduação em institutos isolados (CURY, 2005). Isso permitiu ao INPE, diante da sua necessidade de formar recursos humanos em uma área na qual o país não tinha tradição, que iniciasse a estruturação do seu núcleo de pós-graduação, a partir de 1968 (OLIVEIRA, 1991). Ao mesmo tempo em que o INPE estruturava o seu núcleo de PG, o Decreto 469, de 11/02/1969, ratificou a autorização para o funcionamento de cursos em institutos isolados, com "alto padrão, capaz de contribuir, efetivamente, para o aperfeiçoamento do ensino e da pesquisa nos setores abrangidos". Desde então, a formação de recursos humanos, juntamente com a busca pela autonomia tecnológica, a disseminação de conhecimentos, está entre as missões fundamentais do Instituto.

Quanto à política interna de pós-graduação a importância desta atividade está ratificada no Plano Diretor do Instituto, editado em 2007. No entanto, o Plano traz, além da menção de que esta é uma missão institucional, apenas uma pequena referência a esta competência institucional, recomendando o seu alinhamento aos objetivos do Instituto. Outro documento editado ao longo do processo de planejamento estratégico do INPE, em 2006, denominado "A pós-graduação do INPE", apresenta um panorama das atividades de ensino no Instituto. Entre as recomendações deste documento está a vinculação de temas de dissertações e de teses às ações do plano plurianual sob responsabilidade do INPE, a promoção de uma maior interação com as universidades, centros de pesquisas e empresas estimulando a integração em Ciência, Tecnologia e 
Inovação, e o mapeamento das competências formadas nos programas desde a sua criação. O objetivo de tal mapeamento é dimensionar a contribuição da Instituição no âmbito nacional e internacional, e fornecer subsídios para a organização de discussões internas sobre estratégias para todos os programas de pós-graduação do INPE visando atingir e/ou manter o seu nível de excelência e de equilíbrio entre os interesses internos e externos à Instituição.

A principal referência da política de ensino institucional é o regimento geral da pós-graduação, complementado pelos regimentos específicos dos cursos. Segundo o regimento geral, os cursos do Instituto têm por objetivo capacitar e atualizar recursos humanos nos domínios da ciência e tecnologia e suas aplicações nas áreas espaciais e atmosféricas, bem como em áreas correlatas.

\subsection{Perfil dos mestres e doutores formados no INPE}

Entre os anos de 1968 e 2009 foram realizadas 1943 titulações de mestrado e doutorado nos programas de pós-graduação mantidos pelo INPE (incluindo as titulações dos cursos de Engenharia e Análise de Sistemas, Tecnologias Educacionais, Eletrônica e Comunicações, extintos na década de 70 e 80). Somente nos cursos ainda em desenvolvimento - Meteorologia, Sensoriamento Remoto, Astrofísica, Geofísica Espacial, Engenharia e Tecnologia Espaciais, e Computação Aplicada - foram realizadas 1672 titulações no período (1284 mestrados e 388 doutorados), com a formação de 1485 alunos. O gráfico a seguir apresenta a distribuição dos alunos nos cursos.

Gráfico 1 - Titulações realizadas pelo INPE, entre 1968 e março de 2009

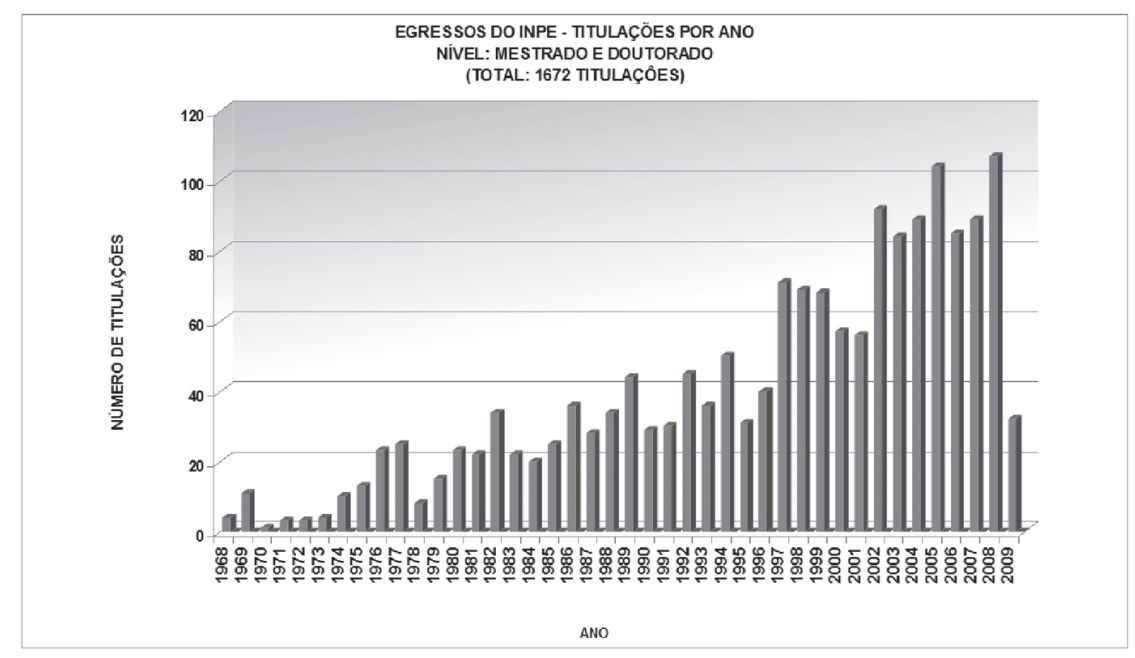


Entre os titulados 73,9\% têm currículo cadastrado na Plataforma Lattes. O grupo mais representado na plataforma é dos egressos do programa de Meteorologia (79,5\%), seguido por Astrofísica com 78,9\%. A distribuição dos currículos dos titulados no INPE segue a tendência dos cadastros de doutores na Plataforma, na qual a maior parte dos currículos concentra-se na área de ciências exatas e da terra (17\%) e a menor nas engenharias (11\%). Esses números podem ser explicados pelo fato de que para pleitear fomentos ao CNPq e a outras agências é indispensável ter os dados cadastrados e, assim, os profissionais que atuam em áreas ligadas à pesquisa têm mais motivação para usar a plataforma Lattes do que aqueles que estão em áreas ligadas à tecnologia e produção, muitos dos quais atuam em indústrias e não fazem pleitos às agências.

\section{Gráfico 2 - Status dos currículos na Plataforma Lattes}

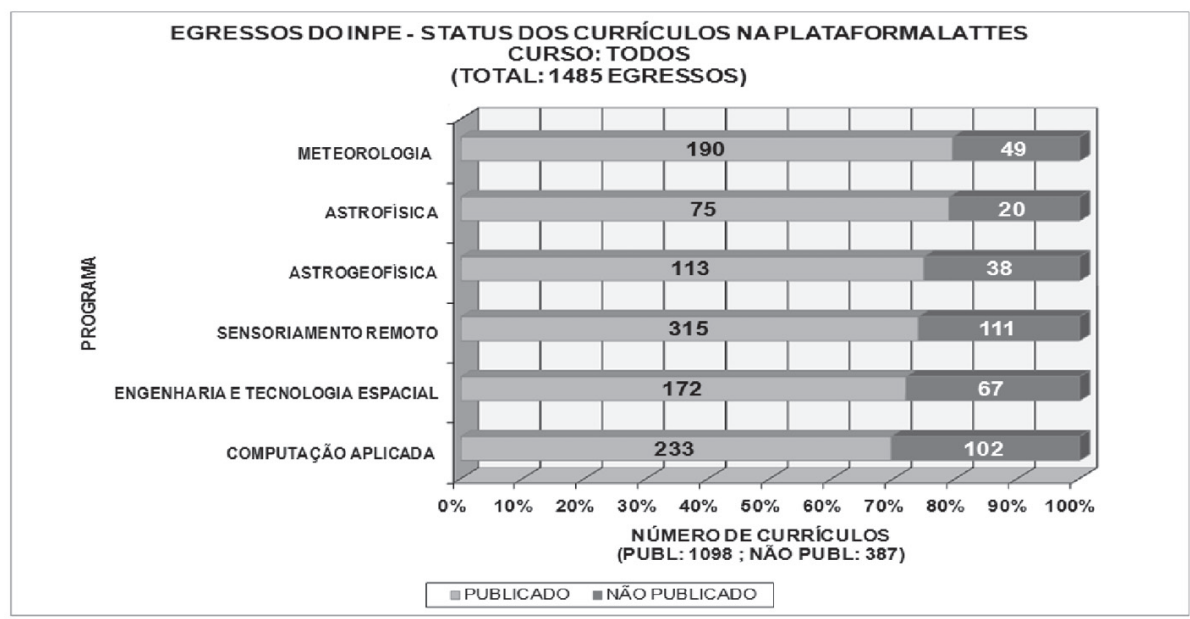

\subsubsection{Trajetória acadêmica}

Os dados sobre o progresso acadêmico dos mestres e doutores titulados no INPE mostram que a maior parte deles tem como última titulação o doutorado. O número de egressos que têm o mestrado como último título, parece alto à primeira vista (33,3\%), uma vez que no Brasil este título é considerado como um "estágio" para o doutorado e não um nível terminal para a pesquisa. Entretanto, comparando-se esses dados com os que se titularam em cursos na área de Geociências em sete universidades brasileiras (OLIVEN, et al, 2002), observa-se que o percentual de mestres formados pelo INPE que prosseguem seus estudos 
(53,9\%) é maior do que a média observada naquelas universidades, nas quais menos da metade dos mestres (40\%) prosseguiram seus estudos pós-graduados stricto sensu. Na USP, cerca de 10\% dos egressos do mestrado em Geociências também concluíram o doutorado, e na UFRJ foram 13,4\% (OLIVEN et al, 2002). Além disso, esse quadro está constantemente sendo alterado, visto que $18 \%$ dos mestres formados no Instituto estão cursando doutorado. A seguir é apresentada a última titulação obtida pelos egressos. Ainda que o pós-doutorado não seja título formal, este foi levado em consideração porque na avaliação acadêmica ter tido essa experiência de treinamento intensivo em pesquisa após o doutorado, principalmente no exterior, indica uma preocupação do pesquisador em desenvolver e adquirir novas habilidades e tem sido valorizado nas avaliações institucionais e pelas agências de financiamento à pesquisa, assim como pela CAPES na avaliação dos programas de PG.

Tabela 1 - Última titulação dos egressos do INPE

\begin{tabular}{lll}
\hline & Última Titulação & Total \\
\hline Mestrado & $33,3 \%$ \\
Doutorado & $47,5 \%$ \\
Pós-Doutorado & $19,2 \%$ \\
\hline
\end{tabular}

As diferenças na trajetória acadêmica dos egressos dos seis cursos dão indicações do valor atribuído aos títulos em cada uma das áreas. Naqueles cursos voltados para a pesquisa básica, como Geofísica Espacial e Astrofísica, áreas em que as possibilidades de inserção e progresso profissional estão intimamente relacionadas ao maior grau de formação obtido, se concentram o maior número de egressos do INPE com pós-doutorado. Por outro lado, nos cursos de Computação Aplicada e Sensoriamento Remoto, voltados para a pesquisa aplicada, a procura pela formação em pesquisa através do pós-doutorado é significativamente menor, e o percentual de egressos que têm mestrado como último título é expressivamente maior do que nos outros cursos.

Tabela 2 - Percentual de egressos do INPE com pós-doutorado, por programa

\begin{tabular}{lc}
\hline \multicolumn{1}{c}{ Programa } & \% por programa \\
\hline Geofísica Espacial & $42 \%$ \\
Astrofísica & $33 \%$ \\
Engenharia e Tecnologia Espacial & $17 \%$ \\
Meteorologia & $12 \%$ \\
Sensoriamento Remoto & $8 \%$ \\
Computação Aplicada & $6 \%$ \\
\hline
\end{tabular}


$\mathrm{Na}$ área de Geofísica Espacial, o percentual de mestres e doutores formados no INPE que realizaram formação no nível de pós-doutorado é ligeiramente inferior à proporção de doutores em Física que fazem pós-doutorado nos Estados Unidos, que foi de $50 \%$ em 2008.

Do total de egressos do Instituto, aproximadamente 20\% concluíram o pós-doutorado, percentual muito próximo da média dos doutores das áreas de engenharia, computação e matemática naquele país, onde a média dos que haviam concluído ou estavam participando de programas de pós-doutorado no ano de 2008 era de $21 \%$ (NSF, 2008).

\section{Gráfico 3 - Formação acadêmica dos egressos, a partir da primeira titulação obtida no INPE}

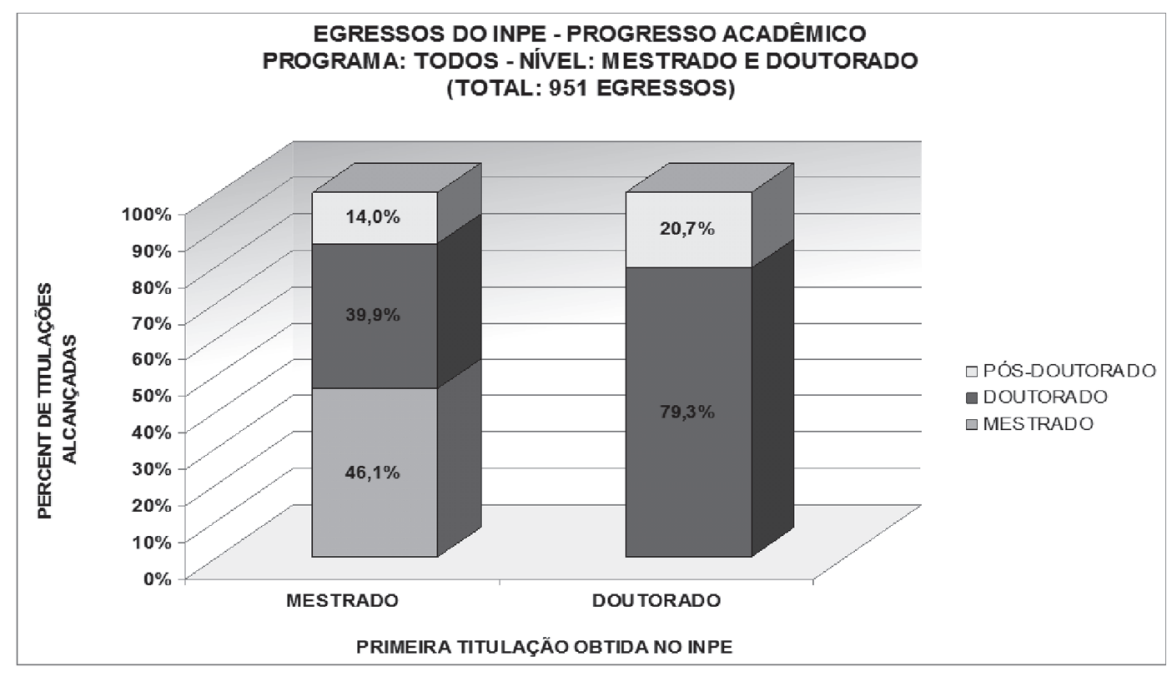

No que se refere ao tempo entre as titulações de mestrado e doutorado daqueles que obtiveram os dois títulos no INPE, observa-se a maioria deles concluiu doutorado entre 5 e 6 anos após o mestrado, tempo muito próximo ao estabelecido pela Capes que é de 48 meses. Essa média sugere que as bolsas concedidas aos alunos contribuem para a continuidade dos estudos. Além disso, ao analisar o perfil profissional daqueles que concluíram o doutorado entre 16 e 21 após o mestrado, observa-se que a maioria é constituída por alunos que já trabalhavam no INPE quando obtiveram o segundo título. Esses resultados mostram a estreita relação entre o fato de estar ou não inserido profissionalmente e a configuração da trajetória acadêmica. 


\section{Gráfico 4 - Tempo entre o mestrado e o doutorado dos alunos que obtiveram as duas titulações no INPE}

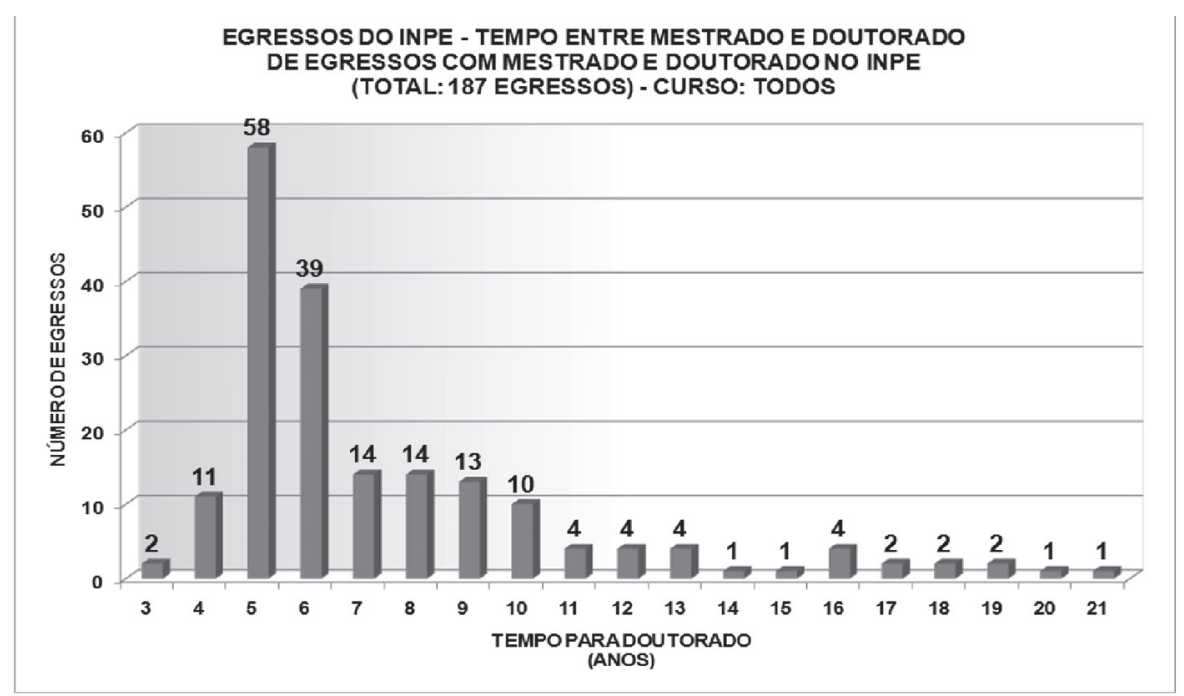

Os resultados da análise da trajetória acadêmica segundo o gênero apontam que há uma forte presença masculina entre os egressos, tanto no mestrado quanto no doutorado. A hipótese de que as diferenças de gênero ainda são marcantes em algumas disciplinas, dentre as quais as ciências exatas, física e engenharia às quais os cursos do Instituto estão relacionados é confirmada ao se analisar a proporção de mulheres tituladas em relação à de homens. As mulheres sempre estiveram em menor número nos programas e representam $27 \%$ dos titulados.

Vários estudos apontam que à medida que se avança nas carreiras em ciência e tecnologia a participação das mulheres decresce (ETZKOWITZ, 2007; EISENHART; FINKEL, 1998; entre outros). Essa tendência é verificada quando se compara a proporção de homens e mulheres titulados no INPE que optaram por continuar seus estudos. Enquanto $58 \%$ dos homens continuaram seus estudos, $43 \%$ das mulheres seguiram na trajetória acadêmica. Contudo, a proporção das mulheres que chegou a concluir o pós-doutorado (23\%) está próxima daquela apresentada pelos homens (26\%). 
Gráfico 5 - Progresso acadêmico dos egressos do INPE, por gênero

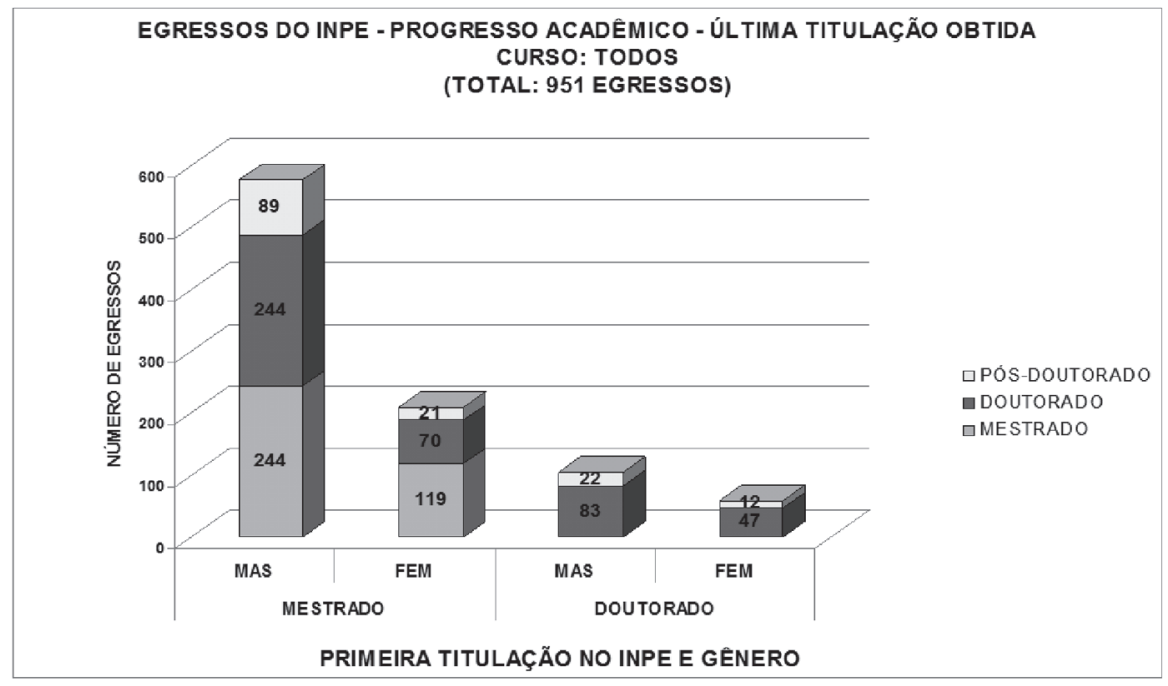

\subsubsection{Atuação profissional}

A área de atuação dos mestres e doutores se caracteriza por um amplo leque de atividades profissionais, no qual os doutores estão em maior proporção na (1) pesquisa e na (2) docência e os mestres estão na (1) pesquisa ou (2) cursando doutorado. Os resultados chamam atenção para a pequena proporção de egressos atuando em atividades de desenvolvimento. $\mathrm{O}$ fato de poucos titulados declararem realizar atividades de desenvolvimento traz relevantes implicações para a avaliação dos cursos frente às principais diretrizes da política para a área espacial. A política espacial fala da promoção da formação e do aprimoramento de recursos humanos altamente qualificados para atuar na integração das universidades e empresas nas atividades espaciais e na efetiva utilização das informações técnico-científicas de interesse espacial, ou seja, para atuar não só na produção de conhecimento como para favorecer pesquisa aplicada e a inovação tecnológica. Para que estas diretrizes sejam concretizadas é necessário planejamento através do qual se reflita, por exemplo, sobre o viés acadêmico dos cursos.

O conjunto de indicadores sobre as funções desempenhadas pelos mestres e doutores revela que aproximadamente um quarto deles tem como principal atividade profissional a docência, a maioria deles doutores, atuando em cursos de graduação em instituições públicas. O título de doutor tem sido cada vez 
mais valorizado nos exames de seleção no setor público. É também neste setor que estão os principais cursos de graduação nas áreas ligadas aos programas do INPE, o que indica que a tendência de concentração de docentes com título de doutor deve ser mantida, dificultando cada vez mais a inserção profissional de mestres neste setor.

\section{Gráfico 6 - Função atual dos egressos do INPE}

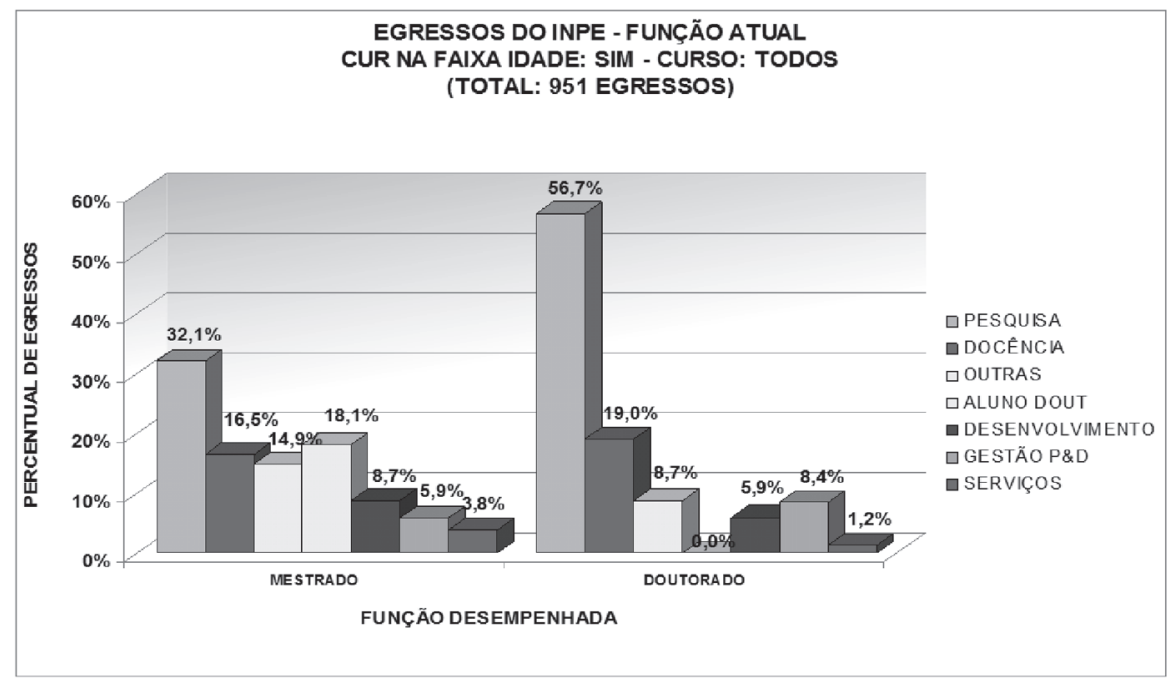

Como dito anteriormente, na definição final da natureza da pós-graduação stricto sensu, o mestrado poderia ser tanto uma etapa na obtenção do grau de doutor como um grau terminal, e seria, então, o doutorado que teria por finalidade propiciar a formação científica nas diferentes áreas do conhecimento. Considerando-se que no Brasil o mestrado é, na prática, um rito de passagem para o doutorado onde efetivamente são formados pesquisadores, o número de mestres que declaram atuar em funções de pesquisa (31,1\%), é surpreendente. $\mathrm{O}$ fato de que todos os mestrados desenvolvidos no INPE são de natureza acadêmica certamente contribui para esse perfil de inserção profissional.

Esse quadro em que aproximadamente $15 \%$ dos mestres atuam em funções de serviço ou outras não acadêmicas contraria a tendência observada por Velloso (2006), com base em dois estudos sobre egressos de mestrado e doutorado no país. Segundo o autor, os mestrados, embora de natureza acadêmica, estariam formando, a partir de meados da década de 90, para ocupações fora da academia. Os resultados indicam não ser esse o perfil dos mestrados do INPE, ratificando 
a especificidade das áreas de conhecimento nas quais os cursos se concentram, que não oferece muitas oportunidades de inserção em ambiente não acadêmico.

Todavia, ao estudar a inserção profissional dos titulados é importante considerar que no contexto atual da ciência e tecnologia emerge a concepção de que novos modos de produção do conhecimento provocam mudanças na pesquisa tradicional e consideram que esta pode ser movida ao mesmo tempo pela busca de entendimento científico e por considerações de uso (STOKES, 2005). Assim, o pequeno número de mestres e doutores que atuam em funções de desenvolvimento ou outras fora da academia mostra o desafio do núcleo de pós-graduação do Instituto em estimular a formação de competências para atuar tanto na produção como na aplicação dos conhecimentos científicos e tecnológicos. Mesmo que alguns cursos do Instituto sejam voltados à pesquisa básica, esta pode ter o valor da "ciência básica inspirada pelo uso" (STOKES, 2005) que é a conjunção das promessas científicas e do seu valor social, que não se detém a um extremo ou outro.

De modo a buscar o alinhamento das atividades de ensino à política nacional das atividades espaciais, que tem como um dos principais objetivos a criação de um ambiente favorável à inovação, é preciso expandir e modernizar o sistema de formação de pessoal, modernizando e consolidando procedimentos de gestão e de política (BRASIL.MCT, 2002). O planejamento, a gestão e a avaliação de resultados devem levar em conta qual o perfil do especialista que se quer formar, apto a atuar em um amplo espectro de atividades.

\subsubsection{Perfil das instituições de destino}

O impulso inicial para a constituição do núcleo de pós-graduação do INPE foi atender à demanda interna por especialistas para atuar nos projetos do Instituto. Desde a década de 60 o quadro das instituições dedicadas à área espacial no Brasil pouco se alterou e o INPE continua sendo o principal órgão civil que desenvolve pesquisa, desenvolvimento e formação em nível de pósgraduação na área.

O levantamento do ramo de atividade econômica das instituições de destino dos mestres e doutores mostra que estes se concentram em instituições de pesquisa e desenvolvimento, seguido por instituições de ensino superior. Há quatro décadas, quando o programa espacial brasileiro estava se organizando os principais atores eram as instituições de pesquisa e desenvolvimento, principalmente o INPE e o CTA (então Centro Técnico de Aeronáutica). Nas últimas décadas um novo ator passou a ter um papel importante no programa 
- as universidades que atuam no ensino e na pesquisa em áreas ligadas à ciência espacial através de cursos de graduação e pós-graduação. Sendo estes os principais atores institucionais, são estas as instituições em que se concentra o maior número de egressos do INPE. O gráfico a seguir apresenta a atividade econômica das instituições de destino dos titulados, segundo a última titulação obtida no Instituto.

\section{Gráfico 7 - Atividade econômica das instituições de destino dos egressos do INPE}

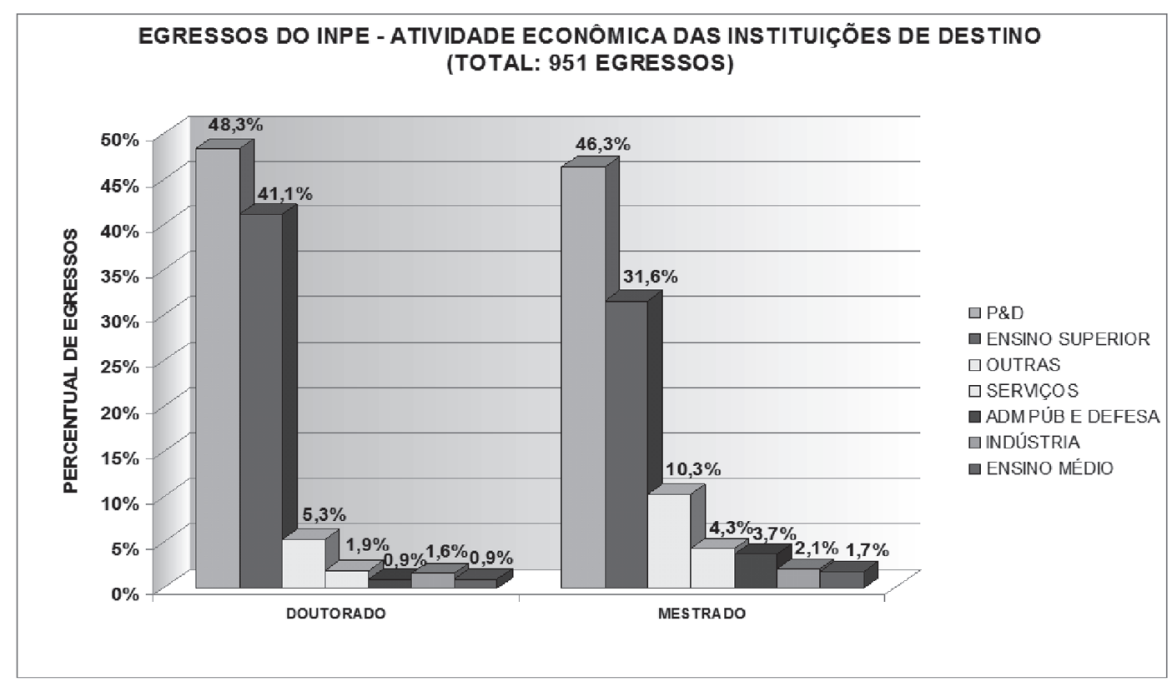

A maior parte dos egressos atua na área aeroespacial, o que aponta não haver grande dispersão entre a área de formação e atuação profissional. Qual é a importância desses titulados atuarem profissionalmente na área de formação? Todo o esforço despendido pelo Instituto tem como objetivo a formação de competências capazes de impulsionar a pesquisa na área espacial, seja no próprio Instituto, em outras instituições de pesquisa e desenvolvimento, de ensino ou indústrias, e a concentração de mestres e doutores na área aeroespacial indica que está sendo atingido o objetivo de fortalecimento da atividade espacial no país, visto que mais de $90 \%$ dos egressos estão em instituições brasileiras. O gráfico a seguir mostra o percentual de titulados na área espacial. Na coluna dos mestres que atuam na área espacial, estão incluídos os que são alunos de doutorado nesta área. 
Gráfico 8 - Área de atuação, por titulação

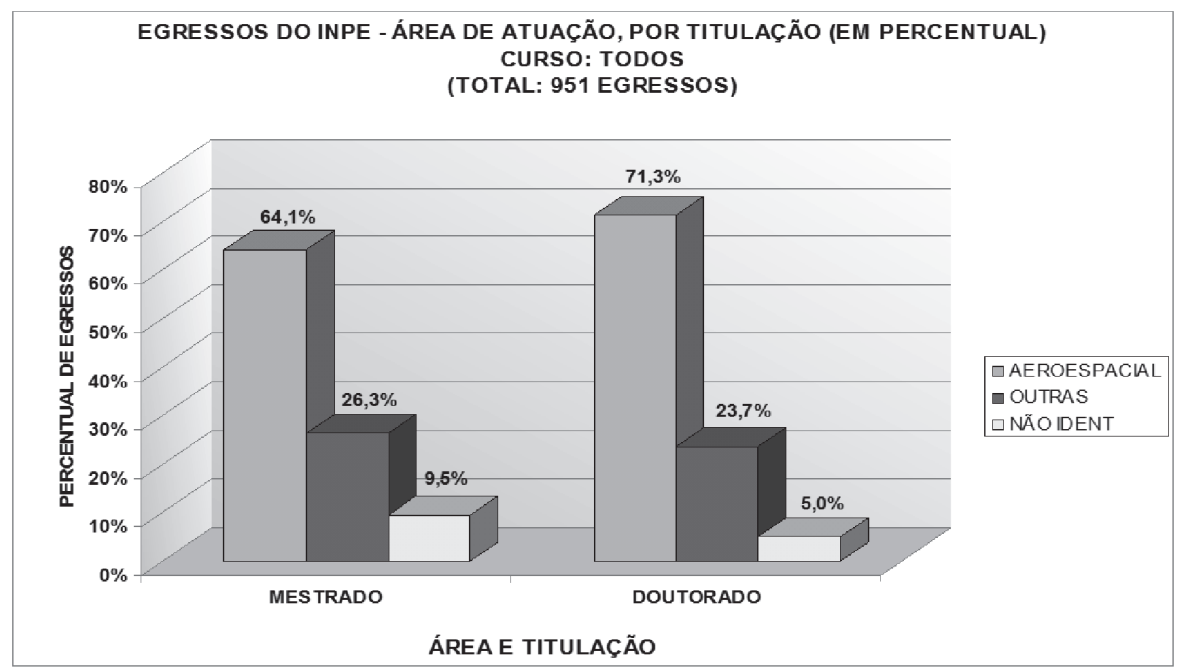

O cenário da inserção profissional dos mestres e doutores mostra a prevalência no setor público, o que já era esperado visto que no Brasil as atividades de pesquisa, desenvolvimento e ensino na área aeroespacial concentram-se neste setor, ao contrário de outros países como os Estados Unidos, por exemplo, onde há um peso determinante das empresas privadas na área espacial (MONSERRAT FILHO, 2007).

Tabela 3 - Setor econômico de atuação dos egressos do INPE

\begin{tabular}{lcc}
\hline \multicolumn{1}{c}{ NÍVEL } & \multicolumn{2}{c}{ SETOR ECONÔMICO } \\
\hline \multirow{2}{*}{ MESTRADO } & PÚBLICO & PRIVADO \\
DOUTORADO & $80,9 \%$ & $19,1 \%$ \\
\hline
\end{tabular}

No setor privado, os mestres atuam principalmente no (1) ensino ou (2) desenvolvimento, e doutores no (1) ensino ou na (2) pesquisa. No setor público, tanto mestres quanto doutores concentram-se na (1) pesquisa e em seguida no (2) ensino. O pequeno número de mestres na pesquisa no setor privado, aliado à exigência do título de doutor como requisito mínimo para ingresso na carreira 
de pesquisa no setor público, sugere que para os mestres as possibilidades de inserção em atividades de pesquisa têm sido cada vez mais reduzidas, com a valorização do doutorado para o desempenho dessa função.

Os egressos com função docente no setor privado são em maior número do curso de Computação Aplicada. O curso com menor número de egressos atuando no setor privado é o de Meteorologia, área em que as possibilidades de trabalho como docente no setor privado é quase nula, uma vez em que cursos de graduação em Meteorologia são oferecidos somente pelo setor público (BRASIL.MEC, 1968), no qual estão os maiores atores institucionais, como o próprio INPE e o Instituto Nacional de Meteorologia (INMET).

\subsubsection{Inserção dos mestres e doutores no INPE}

Fez parte das preocupações deste estudo conhecer a contribuição dos egressos para o próprio INPE. Além da contribuição que os alunos dão ao Instituto ao longo de sua formação, participando dos projetos, pesquisando e publicando em conjunto com os docentes, há um representativo número de egressos que ingressaram no Instituto como servidores efetivos. O gráfico a seguir mostra o número de servidores das carreiras de pesquisa e desenvolvimento que são egressos da pós-graduação do INPE.

\section{Gráfico 9 - Egressos atuando no INPE}

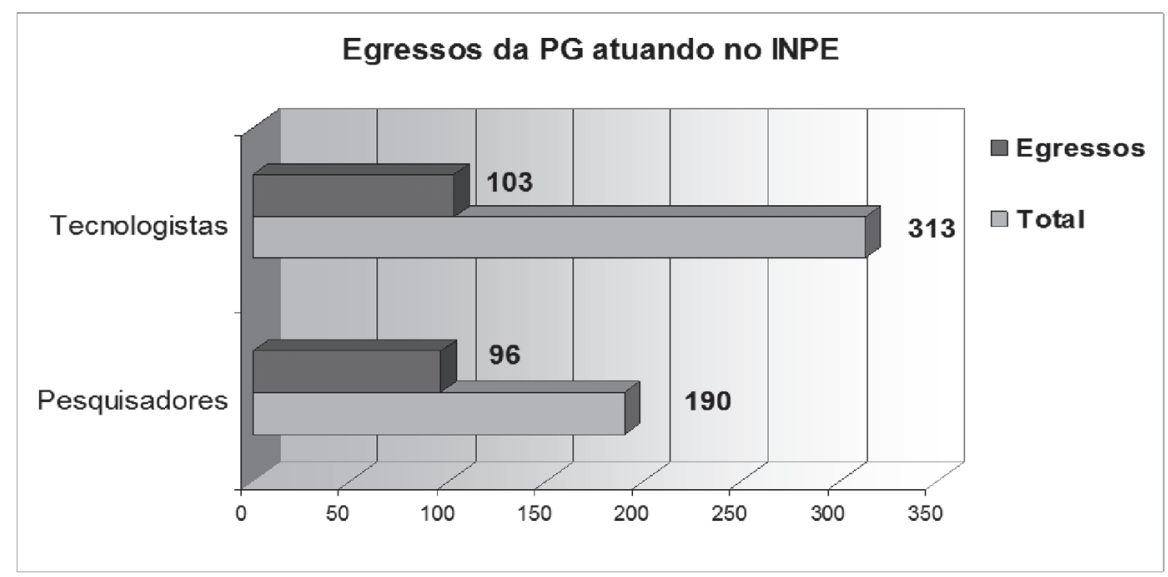


Nos seis concursos realizados pelo INPE entre 1994 e 2006 aproximadamente um terço dos profissionais que foram aprovados e nomeados são egressos do Instituto.

Tabela 4 - Egressos contratados pelo INPE através de concursos, segundo a função, no período 1994-2006

\begin{tabular}{lcc}
\hline \multicolumn{1}{c}{ Função } & Número de contratados & $\begin{array}{c}\text { Percentual de vagas preenchidas } \\
\text { por egressos }\end{array}$ \\
\hline Assistente de Pesquisa & 2 & $100 \%$ \\
Pesquisador & 65 & $45 \%$ \\
Tecnologista & 91 & $27 \%$ \\
\hline
\end{tabular}

Como ocorre em outras unidades de pesquisa, há uma inadequação entre a quantidade de recursos humanos efetivos e os requeridos para a condução das atividades do INPE, que nos últimos anos têm sofrido baixas nos seus quadros sem que tenha ocorrido reposição na mesma proporção. Assim, a manutenção do quadro de recursos humanos tem sido realizada também por outros meios, além dos concursos (BRASIL.MCT, 2007). Entre eles, a utilização de bolsas do Programa de Capacitação Institucional (PCI) custeadas pelo CNPq. Atualmente, aproximadamente $20 \%$ dos bolsistas atuando no INPE através de bolsas PCI são egressos da pós-graduação.

\section{ANÁLISES CONCLUSIVAS}

Qual o perfil dos egressos do INPE? O número de egressos cadastrados na plataforma Lattes (73\%) mostra um claro interesse pelo reconhecimento dos titulados como atuantes em pesquisa e desenvolvimento, através de uma visibilidade proporcionada pela Plataforma; e também a adoção de uma estratégia no sentido de assegurar a sua própria legitimidade no campo científico assim como também as possibilidades de financiamento.

Os resultados mostram que o doutorado é o principal horizonte acadêmico dos titulados. Somando-se o número de doutores e pós-doutores $(66,7 \%)$ observa-se um número bastante expressivo de egressos com formação para a pesquisa. 
O prazo na trajetória de formação entre o mestrado e o doutorado está entre cinco e seis anos, muito próximo do tempo das bolsas concedidas pelas agências de fomento e do prazo de conclusão definido pela Capes, que é de 48 meses, o que sugere que as bolsas das agências têm um peso importante para a trajetória dos alunos do INPE.

Entre os titulados há predominância de homens que, proporcionalmente, são os tiveram trajetória acadêmica mais longa, com a obtenção de títulos de doutor e pós-doutor. Ainda assim, esse perfil acadêmico está sendo alterado, com um terço das mulheres que se titularam mestre no Instituto cursando doutorado atualmente, enquanto que entre os homens são aproximadamente $20 \%$.

As inserções profissionais dos mestres e doutores não apresentam grande variação e se concentram na área de pesquisa. No caso dos mestres essa concentração foi surpreendente dado que a pesquisa espacial no Brasil ocorre principalmente em instituições públicas, nas quais o título de doutor é exigência para a carreira de pesquisa. Esse quadro possivelmente deve ser alterado com as novas contratações no setor público via concurso público, sugerindo que o número de mestres que irão procurar pelo doutorado deve ser ainda maior.

O pequeno número de egressos atuando em atividades de desenvolvimento chama atenção para a necessidade de criação de novas alternativas para inserção desses mestres e doutores, seguindo, por exemplo, as concepções que desde os anos noventa já se configuravam em países cientificamente centrais, nos quais os estilos de treinamento são orientados para variados tipos de atuação profissional, buscando assim atender a demandas de setores da vida social além da academia (VELLOSO, 2006). Essas novas alternativas certamente requerem ações dos gestores do Programa Nacional de Atividades Espaciais, através de políticas de incentivo à agregação de novos atores institucionais, do fortalecimento da política industrial, estimulando o setor empresarial a investir em atividades de pesquisa, desenvolvimento e inovação; mas também requerem ações por parte dos gestores de ensino, para formar especialistas aptos a atuar em uma ampla gama de atividades de pesquisa e desenvolvimento.

Do ponto de vista institucional, observou-se a falta de publicação da política interna da pós-graduação, assim como a ausência de mecanismos de avaliação dos cursos, que são instrumentos fundamentais para a verificação do alinhamento das atividades de ensino aos objetivos da PNAE e da missão do INPE. É necessário sublinhar a importância da efetivação destes mecanismos, além dos regimentos dos cursos já existentes.

Os resultados do impacto da pós-graduação nas atividades espaciais no país, afirmam a relevância da formação de mestres e doutores no INPE, e sugerem que um dos desafios que se põem para os gestores da pós-graduação do INPE 
é a busca por meios e modos de avaliação de desempenho e de impacto que sirvam de subsídios ao planejamento e às ações de formação de competências humanas capazes de conduzir ciência e tecnologia espacial e a inovação, tendo como elementos norteadores as políticas estratégicas de desenvolvimento científico, tecnológico, econômico e social do país.

\section{REFERÊNCIAS}

ALMEIDA JUNIOR, Antonio Ferreira et al. Parecer CFE n ${ }^{\circ}$ 977/65, aprovado em 3 dez. 1965. Revista Brasileira de Educação, Rio de Janeiro, n. 30, p. 162-173, 2005. Disponível em: <http://www.scielo.br/scielo. php? script $=$ sci_arttext\&pid=S1413-24782005000300014\&lng $=$ en\&nrm $=\mathrm{i}$ so >. Acesso em: 02 abr. 2009.

BALBACHEVSKY, Elizabeth. A pós-graduação no Brasil: novos desafios para uma política bem-sucedida. In: BROCK, Colin; SCHWARTZMAN, Simon. Os desafios da educação no Brasil. Rio de Janeiro: Nova Fronteira, 2005.

BRASIL.Agência Espacial Brasileira. Programa Nacional de Atividades Espaciais (PNAE). Brasília: MCT, 2005.

BRASIL.CAPES. Estatísticas. 2009. Disponível em: <http://www.capes. gov.br/estatisticas> Acesso em: 25 mar. 2009.

BRASIL.CAPES. Documento da área de geociências: Avaliação Trienal 2007.CAPES, 2007. Disponível em: <http://www.capes.gov.br/images/ stories/download/

avaliacaotrienal/doc_areas_trienal_2007/2007_Geocencias_Aval2004-2006. pdf $>$. Acesso em: 10 abr. 2009.

BRASIL.CNPq. Dados e estatísticas. 2009. Disponível em < http://lattes. cnpq.br>. Acesso em: 25 mar. 2009.

BRASIL.Decreto-Lei 464, de 11 de fevereiro de 1969. Dispõe sobre o reconhecimento das universidades e dos estabelecimentos isolados de ensino superior. Normas complementares à Lei $\mathbf{n}^{\mathbf{0}}$ 5.540. Brasília, 11/02/1969. Disponível em: < www.planalto.gov.br/CCIVIL/Decreto-Lei/1965-1988/ Del0464.htm>. Acesso em: 02 abr. 2009. 
BRASIL.INPE. Relatório de gestão. 2009. Disponível em: $<$ http://www. inpe.br/dspace/handle/123456789/896>. Acesso em: 10 abr. 2009.

BRASIL. Ministério da Ciência e Tecnologia. Indicadores de Pesquisa Desenvolvimento e Ciência Tecnologia - 2000. Brasília, 2002.

BRASIL.Ministério da Ciência e Tecnologia. Livro Branco: Ciência, Tecnologia e Inovação/Brasília: MCT, 2002. Disponível em: <http://www. itsbrasil.org.br/pages/23/livrobranco.pdf> Acesso em: 20 abr. 2009.

BRASIL.Ministério da Ciência e Tecnologia. Plano de Ação 2007-2010. Brasília, MCT, 2007.

BRASIL.Ministério da Educação. Relatório do Grupo de Trabalho da Reforma Universitária, criado pelo Decreto n 62.937/6. Rio de Janeiro: MEC/MPCG/MF, 1968.

BRASIL. V Plano Nacional de Pós-Graduação. Brasília: Capes. 2004. Disponível em <http://www2.capes.gov.br/rbpg/images/stories/ downloads/RBPG/vol.2_3_mar2005_/185_198_plano_nacional_ posgraduacao_2205_2010.pdf>. Acesso em: 02 abr. 2009.

CURY, Carlos Roberto Jamil. Quadragésimo ano do parecer CFE n ${ }^{\circ}$ 977/65. Revista Brasileira de Educação, Rio de Janeiro, n. 30, p. 7-20, dez. 2005. Disponível em: $<$ http://www.scielo.br/scielo.php?script=sci_arttext\&pid=S1 4134782005000300002\&lng=en\&nrm=iso $>$. Acesso em: 08 abr. 2009.

DELANEY, Ann Marie. Promoting utilization of alumni research: design and implementation strategies. In: ANNUAL FORUM OF THE ASSOCIATION OF INSTITUTIONAL RESEARCH, New Orleans, LA, 1994. Annals.... New Orleans, LA, 1994. Disponível em: <http://www.eric.ed.gov/ERICWebPortal/contentdelivery/servlet/ ERICServlet?accno=ED373614 $>$. Acesso em: 11 out. 2011.

EISENHART, Margaret; FINKEL, Elizabeth et al. Women's science: learning and succeeding from the margins. United States: Chicago, US, 1998.

ETZKOWITZ, Henry. The "Athena Paradox": bridging the gender gap in science. J. Technol. Manag. Innovation, Santiago, Chile, v. 2, n. 1, 2007.

FISCHER, Tânia. Mestrado profissional como prática acadêmica. Rev.Bras. de Pós-Graduação, Brasília, v. 2, n. 4, p. 24-29, jul. 2005. 
HAYASHI, Maria Cristina Innocentini et al. Avaliação de aspectos formais em quatro periódicos científicos na área de educação especial. Revista Brasileira de Educação Especial, Marília, v. 12, n. 3, dez. 2006 . Disponível em: $<$ http://www.scielo.br/scielo.php?script=sci arttext\&pid=S1413-65382006000300006\&lng=en\&nrm=iso $>$. Acesso em: 08 abr. 2009.

INGRAM, Kathleen; HAYNES, Linda; DAVIDSON-SHIVERS, Gayle; IRVIN. Richard. Building an alumni support community: tracking alumni for program evaluation and added value. College Student Journal, USA, 2005. Disponível em $<\mathrm{http}$;/www.freepatentonline.com/article/College-StudentJournal/133606091.html>. Acesso em: 10 out. 2011.

KUENZER, Acácia; MORAES, Maria Célia. Temas e tramas na pósgraduação em educação. Educação e Sociedade, Campinas, v. 26, n. 93, dez. 2005 . Disponível em $<$ http://www.scielo.br/scielo.php?> Acesso em: 22 abr. 2009.

LEAL, Maria do Carmo; COIMBRA JR, Carlos. Avaliação da pós-graduação no Brasil e seu impacto sobre as revistas científicas nacionais: um alerta! Cadernos de Saúde Pública, Rio de Janeiro, v. 24, n. 11, nov. 2008 . Disponível em $<$ http://www.scielo.br/scielo.php?script=sci_arttext\&pid= S0102-311X2008001100001\&lng=pt\&nrm=iso > . Acesso em: 08 abr. 2009. MARTINS, Carlos Benedito. O ensino superior brasileiro nos anos 90. São Paulo Perspectiva, São Paulo, v. 14, n. 1, mar. 2000. Disponível em <http://www.scielo.br/scielo.php?script=sci_arttext\&pid=S010288392000000100006\&lng=en\&nrm=iso $>$. Acesso em: 07 abr. 2009.

MARTINS, Carlos Benedito. A formação do sistema nacional de pósgraduação. Educação Superior no Brasil. Brasília: Capes. 2002.

MONSERRAT FILHO, José. Quem manda no espaço? Revista Brasileira de Direito Aeronáutico e Espacial, Rio de Janeiro, 2007. Disponível em: $<$ http://www.sbda.org.br/revista/Anterior/Ind_ant.htm>. Acesso em: 02 jun. 2009.

MOREIRA, Maria Lígia; VELHO, Lea . Pós-Graduação no Brasil: da concepção "ofertista linear" para "novos modos de produção de conhecimento": implicações para a avaliação. Avaliação, Campinas; Sorocaba, v. 13, p. 67-88, mar. 2008. 
MOREL, Regina Lúcia. Ciência e estado: a política científica no Brasil. São Paulo: T. A. Queiroz, 1979.

NSF. The science and engineering workforce: realizing america's potential, 2003. Disponível em: $<$ http://nsf.gov/nsb/documents/2003/ nsb0369/nsb0369.pdf $>$. Acesso em: 28 maio 2009.

NSF. Postdoc participation of science, engineering, and health doctorate recipients. NSF 08-307, mar 2008. Disponível em: <http://www.nsf.gov/ statistics/infbrief/nsf08307/\#fn2>. Acesso em: 12 jun. 2009.

OECD. Canberra manual: the measurement of scientific and technological activities manual of the measurement of human resources devoted to S\&T. OECD Publ., Paris, 1995. Disponível em: <http://www.oecd.org/ dataoecd/34/0/2096025.pdf> . Acesso em: 02 abr. 2009.

OECD. Frascati manual:Proposed Standard practice for surveys on research and experimental development, OECD Publ., Paris, 2002. Disponível em: $<$ http://www.mct.gov.br/upd_blob/0006/6562.pdf>. Acesso em: 02 abr. 2009.

OLIVEIRA, Fabíola. Caminhos para o espaço: 30 anos de INPE. São Paulo: Contexto. 1991.

OLIVEN, Aravela Campos, et al. Mestres e doutores em física. In:

VELLOSO, J. (Org.). A pós-graduação no Brasil: formação e trabalho de mestres e doutores no país. Brasília: CAPES, 2002. p. 283-304.

PAULA, Maria Carlota. A base Qualis e sua utilização no projeto inserção. In VELLOSO, J. et al. Formação no país ou exterior? Doutores na pósgraduação de excelência. Brasília: CAPES, 2002.

PENA, Mônica Diniz. Acompanhamento de egressos: análise conceitual e sua aplicação no âmbito educacional brasileiro. Educação Tecnológica, Belo Horizonte, v. 5, n. 2, p. 25-30, jul./dez. 2000. Disponível em: $<\mathrm{http} / /$ www2.cefetmg.br/dppg/revista/arqRev/revistan5v2-artigo3.pdf $>$. Acesso em: 29 maio 2009.

SÁ BARRETO, Francisco César. O futuro da pós-graduação brasileira. In: STEINER, João E.; MALNIC, Gerhard (Orgs.). Ensino superior: conceito e dinâmica. São Paulo: Edusp, 2006.

SBPC. Projeto ciência e tecnologia no Brasil. Grupo de Trabalho de Desenvolvimento Científico e Tecnológico, v. 1, 2 e 3. Grupo de Trabalho de 
Infra-Estrutura de Pesquisa e Formação de Recursos Humanos, v. 1, 2 e 3, 2006. Disponível em: <http://www.sbpcnet.org.br/documentos/projetoC\&T. htm>. Acesso em: 05 maio 2009.

SCHWARTZMAN, Simon. Um espaço para a ciência: a formação da comunidade científica no Brasil. Brasília: MCT, 2001.

SCHWARTZMAN, Simon. Pesquisa Universitária e pós-graduação no Brasil. Centro de Gestão e Estudos Estratégicos. Ciência, Tecnologia e Inovação. Brasília, 2008.

SOARES, Maria Suzana (Coord.). A educação superior no Brasil. Porto Alegre: UNESCO, 2002.

SOBRAL, Fernanda. A universidade e o novo modo de produção do conhecimento. Caderno CRH, Salvador, n. 34, p. 265-275, jan./jun. 2001.

STOKES, Donald. O quadrante de Pasteur: A ciência básica e a inovação tecnológica. Campinas: Edunicamp, 2005.

VELHO, Lea. O papel da formação de pesquisadores no sistema de inovação. Ciência e Cultura, Campinas, 2007. Disponível em: $<$ http://cienciaecultura.bvs.br/scielo.php?pid=S00097252007000400013\&script=sci_arttext $>$. Acesso em: 10 jun. 2009.

VELLOSO, Jacques. Mestres e doutores no país: destinos profissionais e políticas de pós-graduação. Cadernos de Pesquisa, São Paulo, v. 34, n. 123, p. 583-611, set./dez. 2004.

VELLOSO, Jacques; VELHO, Lea. Mestrandos e doutorando no país: trajetórias de formação. Brasília: Capes, 2001. Disponível em: $<$ script=sci arttext\&pid=S0101-73302005000400015\&lng=en\&nrm=iso $>$. Acesso em: 08 abr. 2009.

VELLOSO, Jacques. Pós-Graduação: egressos, trabalho e formação no país e no exterior. In: João E. Steiner; Gehrard Malnic. (Org.). Ensino Superior: conceito e dinâmica. São Paulo: EDUSP, 2006. v. 1, p. 177-212.

UNDERWOOD, David; NAULT, Eleanor; FERGUSON, Loreta. Sometimes more is better: development and implementation of a graduate alumni survey to increase response rates and evaluate strategic planning. New Orleans: Association of Institutional Research, 1994. 